\title{
Solar Drying of Greenhouse Crop Residues for Energy Valorization: Modeling and Determination of Optimal Conditions
}

\author{
Maria Guadalupe Pinna-Hernández ${ }^{1,2, *(D)}$, Francisco Gabriel Acien Fernández ${ }^{1,2}$, \\ José Gabriel López Segura ${ }^{3}$ and José Luis Casas López ${ }^{1,2} \mathbb{D}$ \\ 1 Solar Energy Research Centre (CIESOL), Joint Centre University of Almería-CIEMAT, \\ 04120 Almería, Spain; facien@ual.es (F.G.A.F.); jlcasas@ual.es (J.L.C.L.) \\ 2 Department of Chemical Engineering, University of Almería, Carretera de Sacramento s/n, \\ La Cañada de San Urbano, 04120 Almería, Spain \\ 3 IFAPA Research Center, La Cañada, 04120 Almería, Spain; jgabriel.lopez@juntadeandalucia.es \\ * Correspondence: gpinnahernandez@ual.es
}

Received: 24 November 2020; Accepted: 17 December 2020; Published: 19 December 2020

\begin{abstract}
Large amounts of crop residue are produced annually in areas such as Almeria (Spain). These residues have elevated moisture and ash contents, and are also very heterogeneous, which hinders their reutilization. With the aim of facilitating biomass utilization in energy recovery-related processes, a model for solar drying was developed. Experiments were performed inside a greenhouse with tomato and pepper residues, following two strategies (hung or stacked residues). The influence of temperature and relative humidity on the residues' equilibrium moisture was also studied. The results were that a model allowed for determination of the equilibrium moisture as a function of ambient conditions (temperature and relative humidity), with the model's characteristic parameters being different for each crop residue. Regarding the drying process, the results conform to first-order kinetics, with the values of the kinetic constants varying as a function of the crop residues and their arrangement. The variation in equilibrium moisture as a function of the annual variation in ambient conditions (temperature and relative humidity) in Almería means that it would only be possible to dry crop residues inside greenhouse below a moisture level of $0.43 \mathrm{~kg}_{\text {water }} / \mathrm{kg}_{\text {drysolids }}$ ( $30 \%$ water content) from April to November.
\end{abstract}

Keywords: solar drying kinetics; greenhouse crop residue; energy recovery; pre-treatment; natural drying; energy sustainability

\section{Introduction}

The production of crop residues is directly linked to agricultural food production; these residues are left over following harvesting activities, but are also generated by grass, trees, shrubs, and road maintenance. Crop residues can include residual matter from grass cutting, tree pruning, and non-productive plantations. Each crop residue has different characteristics that will determine the most appropriate way to manage it. Crop residue management is continually improving, in an effort to ensure the lowest possible environmental, social, and economic impact, coupled with the best possible recovery for each type of residue [1]. In Spain alone, more than 700,000 tonnes of crop residues are managed annually, only a minor part of which are incinerated or dumped as waste [2]. More than $90 \%$ of crop residues are managed; utilized as biofuels in different processes, such as combustion, pyrolysis, or gasification (amongst others); or composted and recycled.

Almería, a province of the Andalusia region (Spain), has the largest area of greenhouses in the world, at 30,456 ha [3]. This extensive area makes it possible to produce large amounts of horticultural 
crops. However, it consequently generates large amounts of residual biomass. This production is not continuous, as it is subject to considerable variations throughout the year, thus complicating its management. In Almería, the crops with the greatest amount of residual matter are tomatoes and pepper, with up to 758,000 and 345,000 tonnes for year, respectively; this includes the leaves, shoots, and damaged fruit [4]. Such quantities of crop residues have triggered the search for a joint management solution - for example, using it in greenhouses as fuel for heating and carbon dioxide enrichment [5], or in any energy-related application [6], such as gasification or pyrolysis [7], whether at the industrial or domestic scale [8].

Greenhouse crop residues are characterized by great heterogeneity, making it very difficult to use them for energy-related processes [9]. Among the most relevant parameters influencing the energetic use of biomass are its ash and moisture content. Greenhouse crop residues from tomato and pepper contain ash and moisture contents of up to $20 \%$ and $80 \%$, respectively. To reduce the ash content, significant improvements can be made to the methods already used by farmers when removing the plants from the greenhouses, allowing a reduction in ash content to below $8 \%$. However appropriate methods still need to be developed for reducing moisture content. These must take into account the prevailing environmental conditions present in greenhouses throughout the year, which are highly relevant to the crop residue's drying time, as well as to energy saving and low cost requirements. All of this makes the development of efficient solar-drying processes a challenge. Using solar energy in the drying processes permits cost savings and avoids the production of greenhouse gases, thus providing continuity to the supply and ensuring a continuous drying process [10].

Solar drying offers the advantages of being cost-effective and highly sustainable, although there are certain issues related to slow drying rates and dependency on the environmental conditions [11]. Two different solar drying processes can be considered: (i) controlled drying with solar energy and (ii) open drying. In controlled drying with solar energy, temperature, speed, and humidity are controlled during the process, allowing the drying period to be shortened and for high quality, dust-free products to be obtained [12]. The main disadvantages of this process are its high cost and the need for complex equipment. In contrast, open-drying methods are cheaper and do not require complex equipment. Personnel operating these systems require no qualification [12]. However, certain disadvantages do exist, such as the risk of product damage (by birds, insects, and animals), product degradation due to direct solar irradiation exposure, product contamination from dust and atmospheric pollution, product spoiling caused by microorganism growth, and most importantly, losses arising from non-uniformity or insufficient drying during the process. For the solar drying of greenhouse crop residues, it is additionally advantageous that the open solar drying processes can be performed inside the greenhouse, where the environment is more controlled and favorable to drying, thus reducing the drying time and final moisture content [12].

In this work, the open drying of tomato and pepper crop residues inside a greenhouse are studied. The aim is to develop models capable of predicting the drying process as a function of environmental and operational conditions. For this, two strategies were investigated, with crop residues hung or stacked at different heights. Experiments were performed in spring (April-May 2017). To be able to reuse the crop residues in energy-related processes, moisture content has to be reduced to below $30 \%$. Given that no other uses were considered, such as composting or being used as feed, the possibility of biomass degradation was not considered. The challenge was to minimize the time, cost, and energy consumption of the drying process to make it possible to reuse the large volume of greenhouse crop residues produced annually in Almería as an energy source for industrial, agricultural, and domestic applications. 


\section{Materials and Methods}

\subsection{Greenhouse Crop Residues}

Greenhouse crop residues contain a high moisture and ash content, which is mainly composed of carbon, oxygen, and hydrogen, and to a lesser extent, nitrogen, potassium, calcium, magnesium, phosphorus, and sulfur [13]. Chemically, the crop residues are composed of varying proportions of cellulose (40-50\%), hemicellulose (20-30\%), and lignin (10-30\%) [14]. The physical, chemical, and energetic characteristics of greenhouse crop residues vary greatly according to the type of crop, stage, and irrigation, etc. In this work, tomato and pepper greenhouse crop residues were utilized, including stems and leaves but not the fruit; the latter was separated for use in other applications. These crop residues were selected because they are the most commonly grown in Almería, with both crop types being available all year around. Tomato crop residues came from bunch tomato plantations, while pepper residues came from Italian peppers; both crops have a long cycle with the plantations harvested throughout the months of April and May. Previous data show that these crop residues have moisture contents ranging from 29.6 to $82.6 \%$, respectively, ash contents from 6.4 to $35.5 \%$, and net calorific values from 1,529 to $1,727 \mathrm{~kJ} / \mathrm{kg}$, thus confirming their great variability [15].

\subsection{Moisture Context}

The characterization of the greenhouse crop residues was performed in accordance with the European Committee for Standardization (CEN) and with AENOR (the Spanish agency for CEN). The UNE EN 14774-1 standard [16] was used to determine the moisture content, for which prior sample preparation is indicated. Different plant components are classified into stems, leaves, raffia, rings, and fruit, and then separated. The stems and leaves are considered together and chopped homogeneously for moisture determination. Once the samples have been separated and homogenized, they are introduced into a flask at $105^{\circ} \mathrm{C}$, and each tray is weighed twice-once at $24 \mathrm{~h}$ and once at $48 \mathrm{~h}$. This ensures that the sample has reached a constant weight and there is no more water loss (equilibrium moisture). According to the UNE EN 14774-1 standard, moisture (X) was determined as (Equation (1)):

$$
X=\frac{\text { Water content }}{\text { Dry weight }} \times 100
$$

\subsection{Solar-Drying Trials}

The solar drying of tomato and pepper crop residues inside a greenhouse was studied. The greenhouse where experiments were performed was equipped with sensors for online measurement of the environmental conditions inside the greenhouse (temperature, relative humidity, and wind speed). Two methods were studied: (i) hanging or (ii) stacking the plants. The hanging arrangement (which is the same arrangement as in cultivation and production) has the advantages of simplicity and minimal manpower required; it also reduces drying time. Conversely, disadvantages are that the greenhouse is occupied for long periods and it is difficult to later remove the dried biomass. In contrast, the stacked arrangement requires more manpower to process the greenhouse crop residues and increases the drying time; however, less of the space in the greenhouse is occupied.

In hanging method trials, in each experiment, up to 120 tomato and pepper plants were cut and hung inside the greenhouse for drying. Four plants were initially processed to determine the initial moisture content. Periodically, three plants were randomly collected and their moisture content measured. Measurements were performed every two days. Regarding the trials in which the plants were stacked, the experiments were performed in 1 cubic meter metal containers (Figure 1), adapted to store the greenhouse crop residues at different heights. This allows air circulation through the stacked biomass and making it easier to weigh the whole container, so as to determine the weight loss. To do this, the containers were weighed empty before being weighed full of the greenhouse crop residues 
(which were stacked at different heights, at 1.00, 0.66, and $0.33 \mathrm{~m}$ ). The weight of the containers was measured every two days.

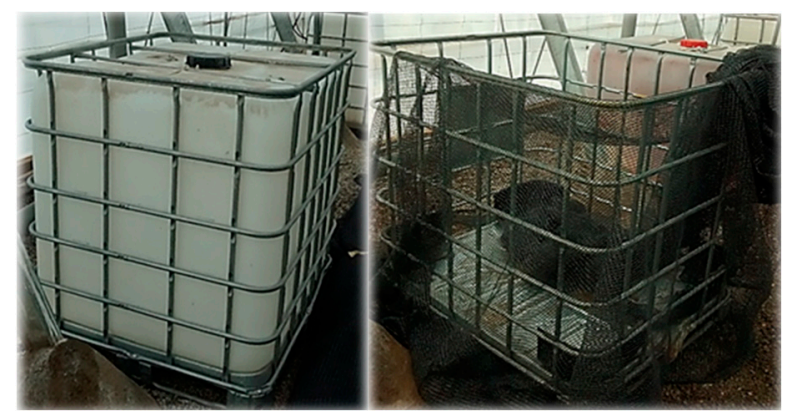

Figure 1. Experimental setup used for the stacked crop residue drying trials.

\subsection{Equilibrium Moisture}

Equilibrium moisture determines the drying phenomena, because it imposes the lowest moisture content of the biomass in equilibrium with the environment in which it is located, as a function of the ambient temperature and relative humidity [17]. The equilibrium moisture of tomato and pepper crop residues as a function of temperature and relative humidity was experimentally measured. For this, different equipment was used, such as an oven $\left(100{ }^{\circ} \mathrm{C}\right.$ and $0 \%$ relative humidity), a growth chamber ( $23.5{ }^{\circ} \mathrm{C}$ and $52.3 \%$ of relative humidity), and a cool chamber $\left(4{ }^{\circ} \mathrm{C}\right.$ and $100 \%$ relative humidity). Samples of both the hung and stacked crop residues were taken at the end of the experiments and subjected to these very different conditions until the weight was constant, at which point the moisture content was determined.

\section{Results and Discussion}

\subsection{Drying Tests}

According to the procedures already presented (Section 2.3.), the variation over time in the moisture content of the tomato crop residues that were hung or stacked in the greenhouse at different heights was measured. The experiments were performed during April and May. The mean daily temperature and relative moisture were $23.5^{\circ} \mathrm{C}$ and $52 \%$ for the stacking arrangement, and $21.7^{\circ} \mathrm{C}$ and $62 \%$ for the hanging arrangement. The results show that the moisture content decreased over time, and that this decrease varied according to the crop and the crop residue arrangement (Figure 2). The initial moisture content of the tomato crop residues was $5.8 \mathrm{~kg}_{\text {water }} / \mathrm{kg}_{\text {drysolids. }}$. When hung, this was reduced as little as $0.12 \mathrm{~kg}_{\text {water }} / \mathrm{kg}_{\text {drysolids }}$ after 36 days, whereas when the crop residues were stacked at a height of $1.0 \mathrm{~m}$, the reduction was $0.32 \mathrm{~kg}_{\text {water }} / \mathrm{kg}_{\text {drysolids. }}$. The minimum final moisture content was achieved when the crop residues were stacked, reducing from 0.30 to $0.29 \mathrm{~kg}_{\text {water }} / \mathrm{kg}_{\text {drysolids }}$ when the height of the stacked crop residues was lowered from 1.0 to $0.66 \mathrm{~m}$. The lowest moisture constant was $0.30 \mathrm{~kg}_{\text {water }} / \mathrm{kg}_{\text {drysolids }}$ at the $0.33 \mathrm{~m}$ height. Regarding the pepper crop residues, the initial moisture content was lower, up to $4.08 \mathrm{~kg}_{\text {water }} / \mathrm{kg}_{\text {drysolids. }}$. This also reduced over time up to values of $0.06 \mathrm{~kg}$ water $/ \mathrm{kg}_{\text {drysolids }}$ after 37 days in the hanging arrangement. The final moisture content was minimal when the crop residues were hung whereas this reduction was less, from 0.38 to 0.12 and $0.08 \mathrm{~kg}_{\text {water }} / \mathrm{kg}_{\text {drysolids }}$ when the crop residues were stacked at heights of 1.0, 0.66 and $0.33 \mathrm{~m}$, respectively. In both types of crop residues and plant arrangements, low moisture values were obtained, although these were lower for the hung crop residues due to the improved water transfer process, which is more difficult to achieve in the stacked biomass. 

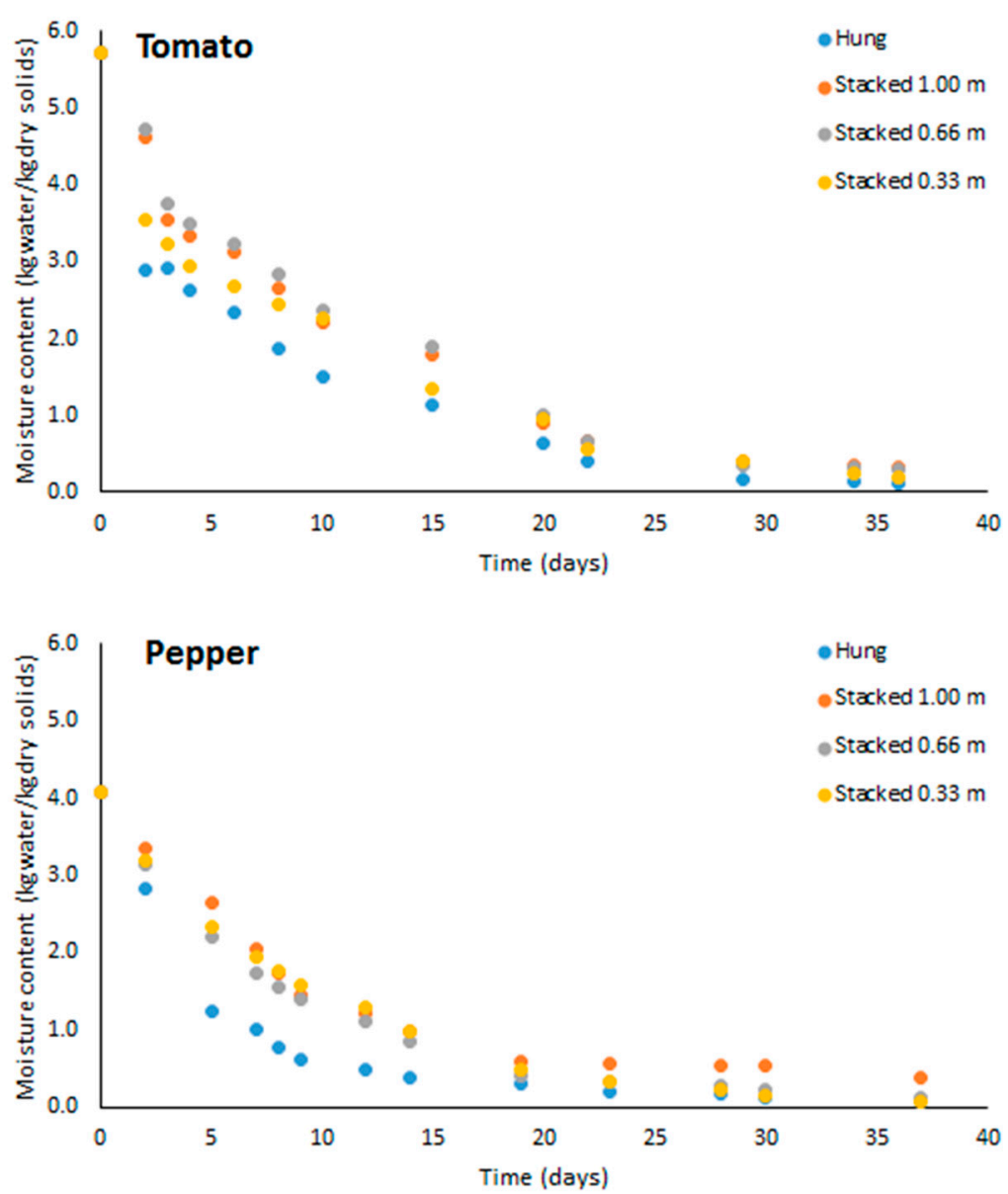

Figure 2. Variation in the moisture content of the tomato and pepper crop residues as a function of time and the plant arrangement during the drying process.

The moisture content decreases more rapidly over the first few days, because the difference is larger between the biomass moisture content, and the moisture content that is in equilibrium with the environmental conditions prevails during the drying process. To predict the drying process, different models can be applied, all of which require knowing the equilibrium moisture as a function of the prevailing conditions. To accomplish this, experimental measurements were performed to ascertain the equilibrium moisture by exposing the crop residues to different temperature and relative humidity conditions (Table 1). The results show that the equilibrium moisture is quite similar for both the crop residues considered, being a function of the ambient temperature and relative humidity to which the crop residues are exposed. No variations were observed between the two different arrangements considered, i.e., hung or stacked (Table 1). The equilibrium moisture of the tomato crop residues ranged from $0.19 \mathrm{~kg}_{\text {water }} \mathrm{kg}_{\text {drysolids }}$ when exposed to high relative humidity $(95 \%)$, in spite of low temperature $\left(-4{ }^{\circ} \mathrm{C}\right)$, down to $0.01 \mathrm{~kg}_{\text {water }} / \mathrm{kg}_{\text {drysolids }}$ when exposed to low relative humidity $(0 \%)$ and high temperature $\left(105^{\circ} \mathrm{C}\right)$. Similar values were obtained for the pepper crop residues, ranging from 0.18 to $0.00 \mathrm{~kg}_{\text {water }} / \mathrm{kg}_{\text {drysolids }}$ when the temperature and relative humidity ranged from $-4{ }^{\circ} \mathrm{C}$ and $95 \%$ to $105^{\circ} \mathrm{C}$ and $0 \%$, respectively. 
Table 1. Experimental values of the moisture in equilibrium with air at different temperatures and relative moisture. Data from the two crop residues and two arrangements already considered.

\begin{tabular}{|c|c|c|c|c|}
\hline $\begin{array}{c}\text { Crop } \\
\text { Residue }\end{array}$ & $\begin{array}{c}\text { Crop } \\
\text { Arrangement }\end{array}$ & $\begin{array}{c}\text { Temperature } \\
\left({ }^{\circ} \mathrm{C}\right)\end{array}$ & $\begin{array}{c}\text { Relative Moisture } \\
(\%)\end{array}$ & $\begin{array}{l}\text { Equilibrium Moisture } \\
\left(\mathrm{kg}_{\text {water }} / \mathrm{kg}_{\text {drysolids }}\right)\end{array}$ \\
\hline \multirow{6}{*}{ Tomato } & \multirow{3}{*}{ Hung } & 105.0 & 0 & 0.01 \\
\hline & & 23.5 & 52 & 0.06 \\
\hline & & -4.0 & 95 & 0.19 \\
\hline & \multirow{3}{*}{ Stacked } & 105.0 & 0 & 0.01 \\
\hline & & 23.5 & 52 & 0.09 \\
\hline & & -4.0 & 95 & 0.19 \\
\hline \multirow{6}{*}{ Pepper } & \multirow{3}{*}{ Hung } & 105.0 & 0 & 0.00 \\
\hline & & 23.5 & 52 & 0.07 \\
\hline & & -4.0 & 95 & 0.16 \\
\hline & \multirow{3}{*}{ Stacked } & 105.0 & 0 & 0.00 \\
\hline & & 23.5 & 52 & 0.08 \\
\hline & & -4.0 & 95 & 0.18 \\
\hline
\end{tabular}

\subsection{Modeling the Drying Process}

To model the influence of temperature and relative humidity on the equilibrium moisture of both crop residues, different equations have been proposed, one of the most widely used being the Guggenheim-Anderson-de Boer (GAB) model $[17,18]$. According to this model, the equilibrium moisture $\left(X_{e}\right)$ can be calculated as a function of temperature $(T)$, and water activity $(a)$ can be calculated as the relative humidity divided by 100 (Equation (2)). This equation has three characteristic parameters $\left(b_{1}, b_{2}\right.$, and $\left.b_{3}\right)$ that must be experimentally determined.

$$
X_{e}=b_{1} \cdot e^{\frac{b_{2}}{T}} \cdot\left(\frac{a}{(1-a)^{b_{3}}}\right)
$$

By using the experimental data (Table 1) already described, the characteristic parameter values $\left(b_{1}, b_{2}\right.$, and $\left.b_{3}\right)$ of the GAB model were determined (Table 2$)$. The determined values are similar for both types of residues, being analogous to those already reported for other materials.

Table 2. Values for the characteristic parameters of the Guggenheim-Anderson-de Boer (GAB) model, determined from experimental measurements of the equilibrium moisture at different temperatures and relative moisture as a function of the crop residue.

\begin{tabular}{cccc}
\hline Crop & $\boldsymbol{b}_{\mathbf{1}}$ & $\boldsymbol{b}_{\mathbf{2}}$ & $\boldsymbol{b}_{\mathbf{3}}$ \\
\hline Tomato & 0.007 & 21.857 & 2.960 \\
Pepper & 0.014 & 17.336 & 2.320 \\
\hline
\end{tabular}

The GAB model allows one to predict the equilibrium moisture for the two crop residues already studied (Figure 3). Thus, under the experimental conditions used during the drying experiments inside the greenhouse $\left(23.5^{\circ} \mathrm{C}\right.$ and $52 \%$ of relative humidity), the moisture content was 0.014 and $0.07 \mathrm{~kg}_{\text {water }} \mathrm{kg}_{\text {drysolids }}$ for the tomato and pepper crop residues, respectively. The equilibrium moisture simulated from the model generated 0.076 and $0.081 \mathrm{~kg}_{\text {water }} / \mathrm{kg}_{\text {drysolids }}$ for the tomato and pepper crop residues, respectively; this means that in the drying experiments, both crop residues achieved a final moisture content close to the equilibrium limit value. 


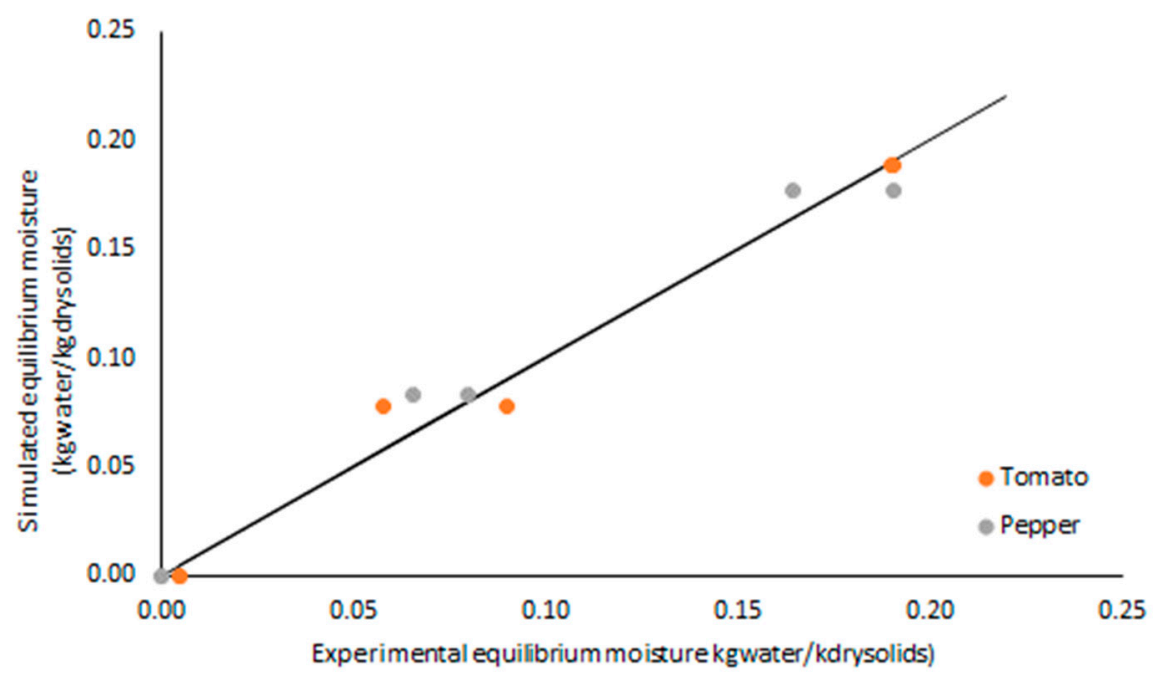

Figure 3. Correlation between the experimental and simulated values of the equilibrium moisture content, determined under different conditions with both crop residue types. The simulated values were obtained using the proposed model, and the characteristic parameter values of the model were determined experimentally.

To use model the drying process, different kinetic models can be considered, such as zero-order, first-order, and second-order kinetic. The first-order kinetic model performed best. Considering first-order kinetics, the variation in moisture over time is a linear function of the driving force, and thus is the difference between the moisture level and the level at equilibrium (Equation (3)). By integrating this equation, one finds that the kinetic constant $(k)$ can be determined by determining the slope of the long transformer moisture concentration versus time (Equation (4)). Once the kinetic constant is known, the variation in the moisture level over time can be simulated using Equation (5).

$$
\begin{gathered}
\frac{d X}{d t}=k\left(X-X_{e}\right) \\
\operatorname{Ln}\left(\frac{X_{e}-X_{i}}{X_{e}-X}\right)=k t \\
X=X_{e}-\left(X_{e}-X_{i}\right) e^{-k t}
\end{gathered}
$$

The results show that the first-order kinetic model adequately fits the behavior of the two crop residues studied (Figure 4). Moreover, the first-order kinetic model fits the behavior of the drying process, whatever the arrangement of the crop residues. The first-order kinetic constant values determined from the experimental data are summarized in Table 3. The results show that for both crop residues, the hanging arrangement of the crops provides a more rapid drying process, with a higher kinetic-constant value than when using the stacking arrangement. For tomato, the first-order kinetic constant value was 0.129 day $^{-1}$, whereas for pepper it was slightly higher, at 0.158 day $^{-1}$. Regarding the stacked biomass, the first-order kinetic constant value also increased when the stacking height was reduced, ranging from 0.093 to 0.101 day $^{-1}$ for tomato, and from 0.086 to 0.122 day $^{-1}$ for pepper. These figures agree with the expected behavior, because the hanging arrangement exposes a larger crop surface area and a creates potentially higher heat/mass transfer capacity for water removal from the crop residues than the stacking arrangement. Furthermore, the surface area and heat/mass transfer capacity increases when the height of stacked biomass is reduced. However, the actual differences between the two crop residues studied are minimal, even when considering the different arrangements. Therefore, this indicates that the main phenomena determining the process velocity is the internal water diffusion within the crop residues, rather than the water evaporation from the crop residue surface to the atmosphere. A more detailed analysis of the phenomena taking place in the drying 
process could be performed in order to quantify the diffusion velocity of the water in the crop residues, and how one could modify it to accelerate the process. Nonetheless, from an applied standpoint, what is more relevant is applying the already developed models to determine the optimal conditions for drying crop residues under real conditions, as a function of the temperature and relative humidity inside the greenhouse.
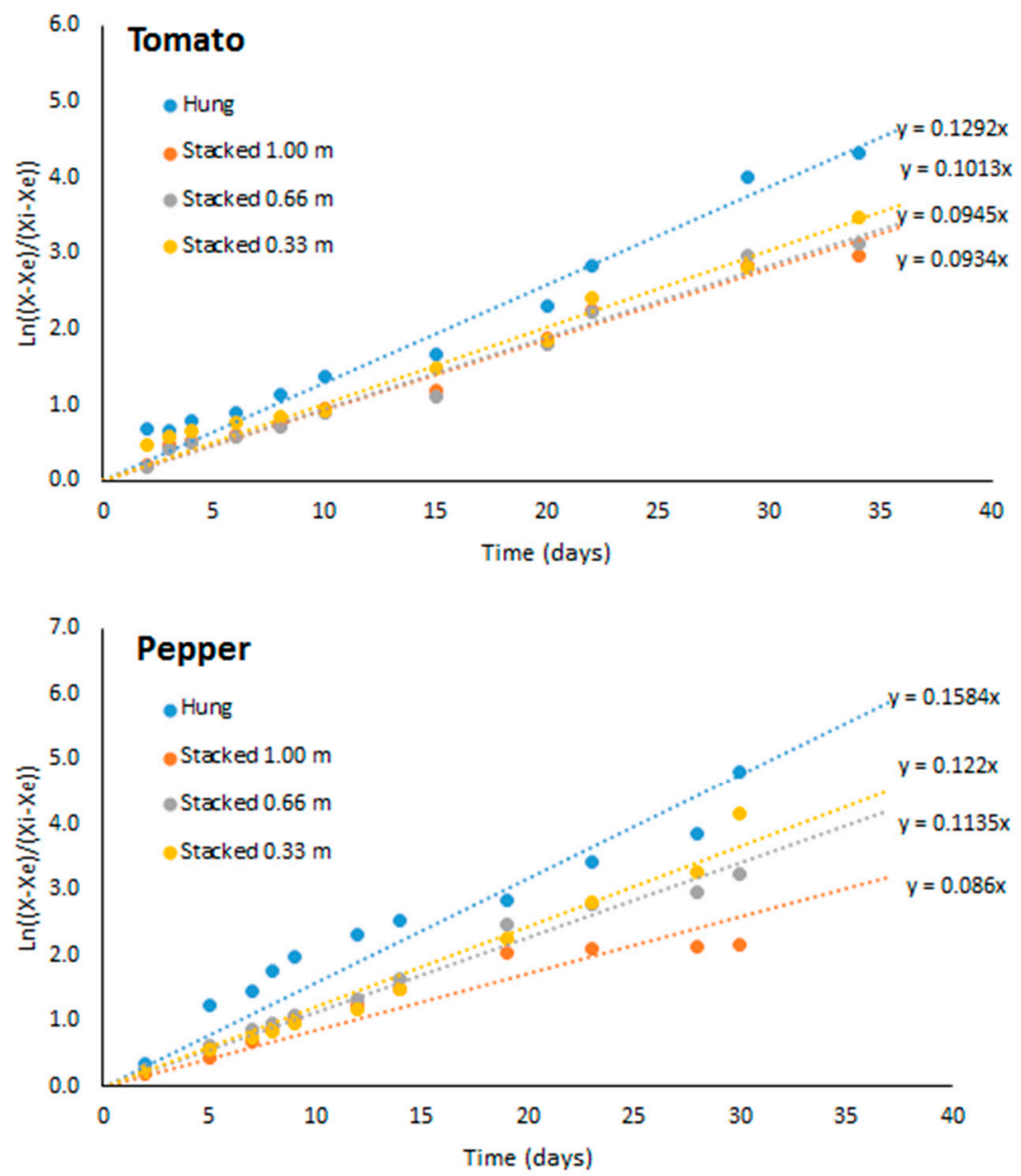

Figure 4. Graphical representation of the drying process considering first-order kinetics (Equation (4)).

Table 3. Values for the first-order kinetic constant $(k)$ experimentally determined for each crop residue type and arrangement. Values were obtained by fitting the experimental results (Figure 2) to Equation (4).

\begin{tabular}{ccc}
\hline & $\boldsymbol{k}$ day $^{\mathbf{- 1}}$ (Tomato) & $\boldsymbol{k}$ day $^{\mathbf{1}}$ (Pepper) \\
\hline Hung & 0.129 & 0.158 \\
\hline Stacked $1.00 \mathrm{~m}$ & 0.093 & 0.086 \\
\hline Stacked 0.66 m & 0.095 & 0.114 \\
\hline Stacked 0.33 m & 0.101 & 0.122 \\
\hline
\end{tabular}

\subsection{Drying Simulations}

The accuracy of the proposed model in predicting the moisture content of the crop residues as a function of time and environmental conditions was verified. Figure 5 shows that the model allows one to simulate the moisture content of the tomato and pepper crop residues, and both arrangements, under the experimental conditions tested. To apply the model to other conditions (Figure 6), the annual variation in temperature and relative humidity for Almería was obtained from 
databases [19]. The results show that the mean daily temperature ranges from 11.8 to $24.8^{\circ} \mathrm{C}$ from January to July, whereas for the same dates, the relative humidity ranges from $67 \%$ to $60 \%$. Variation in the ambient conditions modifies the equilibrium moisture of both the tomato and pepper crops over the annual cycle. The equilibrium moisture of tomato ranges from 0.75 to $0.14 \mathrm{~kg}_{\text {water }} / \mathrm{kg}_{\text {drysolids }}$ from June to July, whereas for pepper, it varies from 0.52 to $0.13 \mathrm{~kg}_{\text {water }} / \mathrm{kg}_{\text {drysolids. }}$. Considering the target value of $0.43 \mathrm{~kg}_{\text {water }} / \mathrm{kg}_{\text {drysolids }}$ (equivalent to $30 \%$ moisture), the pepper crop residues can be dried below this limit from March to November, but for the tomato crop residues, it is only possible to do so in the period from April to September.
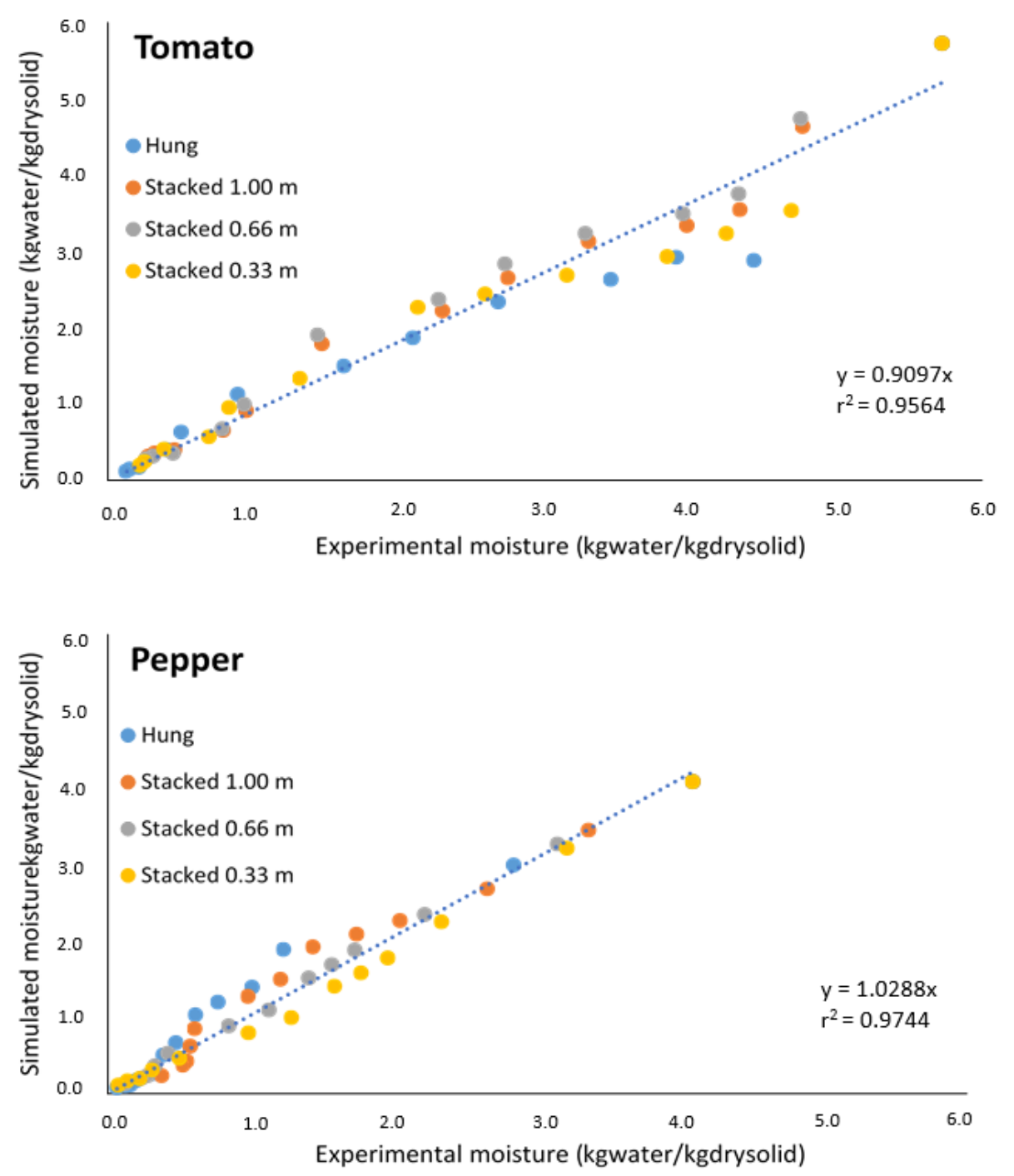

Figure 5. Relationship between the experimental and simulated measurements of the moisture content for both crop residues and the different arrangements, using the proposed models.

Moreover, even if the equilibrium moisture of the crop residue allows one to achieve the target moisture at any time, the process' kinetics might be too low to make it feasible. For this reason, the model has been used to simulate the drying processes (Figure 6) of both crop residues during two different months (April and June), corresponding to the period when most of the crops are removed from Almería greenhouses. The data confirm that pepper crop residues are more easily dried than tomato crop residues, regardless of the month. They also confirm that the hanging arrangement reduces the time required to achieve the target moisture (Figure 6). The drying times necessary to reach the target moisture will depend on the type of residue and the arrangement of the plants. During the 
month of April, the drying time for greenhouse crop residues of tomato and pepper in the hanging arrangement is 30 days and 19 days, respectively, whereas, for the stacking arrangement, the drying time required would be more than 30 days for tomato crop residues and 26 days for pepper crop residues at heights of 0.66 and $0.33 \mathrm{~m}$. As for the month of June, the drying time for the hanging arrangement is 24 and 17 days for greenhouse crop residues of tomato and pepper, respectively. As expected, the drying times are longer for the stacking arrangement, with values greater than 30 days for tomato crop residues, and 24 and 22 days for pepper crop residues at heights of 0.66 and $0.33 \mathrm{~m}$, respectively.

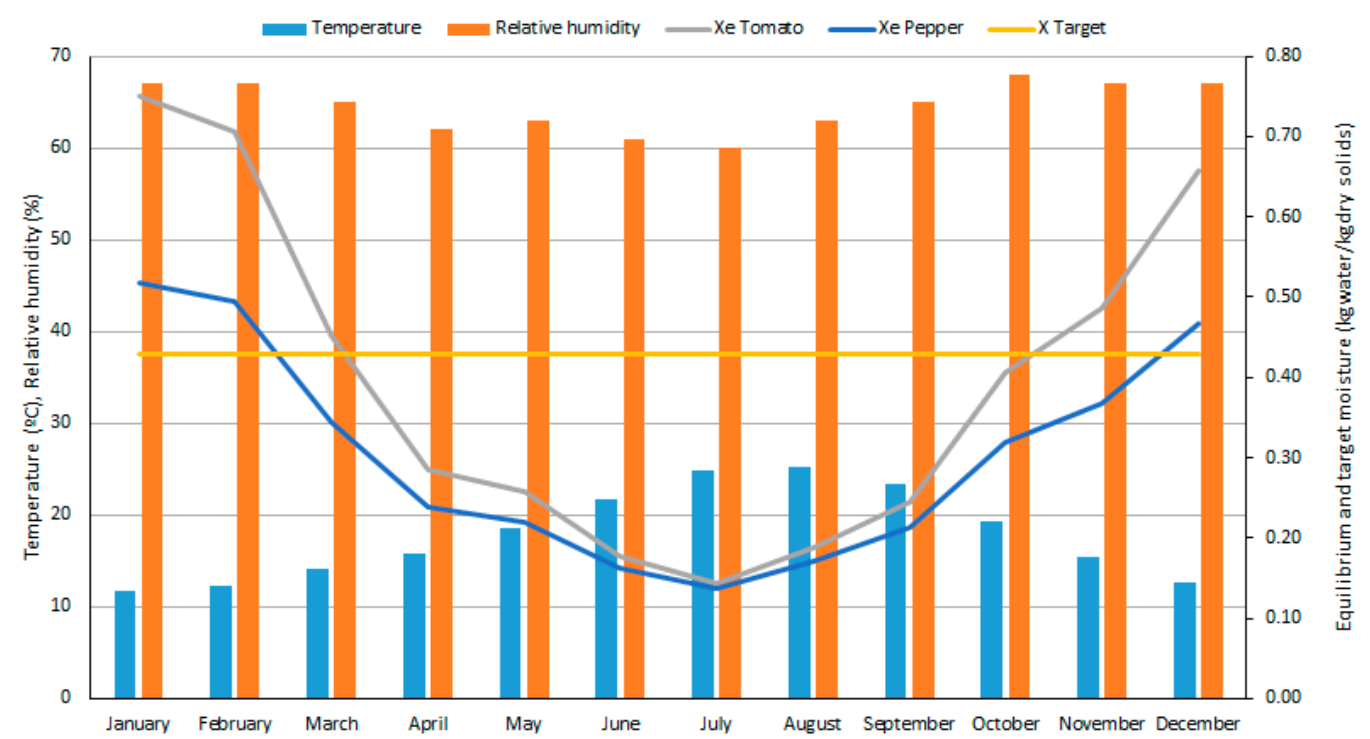

Figure 6. Annual variation in temperature and relative humidity in Almería [19], and their influence on the equilibrium humidity of both the tomato and pepper crop residues. The target moisture represents the maximum moisture suitable for further processing of the crop residues; for this reason, it is included as a reference value to be achieved.

Nevertheless, the times required to achieve target moisture are too long, especially in April, when it can take up to 30 days in the case of tomatoes, even when using the hanging arrangement. For farmers, the best option is to stack the crop residues rather than hanging them to dry, thus freeing up the greenhouse more quickly for consecutive production cycles. Even in this scenario, with the crop residues stacked, the time required to achieve the target moisture is lengthy.

\section{Conclusions}

The drying of tomato and pepper crop residues inside a greenhouse was studied using two different configurations, hanging and stacking, and at different stacking heights. The results demonstrate that these crop residues can be dried below $30 \%$ water content inside a greenhouse, and that the time required to achieve this target moisture is lower for pepper than for tomato. Moreover, the time is shortened when the crop residues are hung rather than stacked, and the drying time is also reduced when the stacked biomass height is lower. The drying velocity is determined by the equilibrium moisture, and to obtain it we employed the GAB model that consider ambient conditions (temperature and relative humidity) that the crop residues are exposed. Using this model, we also modelled the kinetics of the drying process. A first-order kinetic was shown to fit the experimental data, allowing us to determine the kinetic constant for the residues of each crop and their arrangement. The resulting model also allows us to determine the dates when the crop residues can be dried below the 30\% water content limit value. In Almería, this would only be possible from April to November. In addition, the model can be utilized to determine the drying time for different dates, for each crop, or for each 
arrangement strategy. The data confirm that the drying time achieved in April is nearly 30 days, whatever the crop and arrangement. However, the drying time is much quicker in June, dropping to as low as 17 days for peppers when hung. The data and models provided here will make it possible to improve the decision-making process that farmers perform when managing their crops.

Author Contributions: Conceptualization, M.G.P.-H., F.G.A.F., and J.G.L.S.; methodology, M.G.P.-H., F.G.A.F., and J.L.C.L.; validation, M.G.P.-H., F.G.A.F., and J.G.L.S.; formal analysis, M.G.P.-H., F.G.A.F., and J.G.L.S.; investigation, M.G.P.-H., F.G.A.F., and J.G.L.S.; writing-review and editing, M.G.P.-H., F.G.A.F., J.G.L.S., and J.L.C.L. All authors have read and agreed to the published version of the manuscript.

Funding: This research received external funding (R\&D Project the framework of the Feder-Andalucía 2014-2020 operational programme, UAL18-TEP-A055-B), of the Ministry of Economy, Knowledge, Business and University of the Andalusian Regional Government, the University of Almeria, and ERDF funds.

Acknowledgments: The R\&D Project the framework of the Feder-Andalucía 2014-2020 operational programme, UAL18-TEP-A055-B. Furthemore, Authors would like to thanks the Solar Energy Research Centre (CIESOL), Joint Centre University of Almería-CIEMAT, and IFAPA Research Center, La Cañada, Almería, Spain, for their support.

Conflicts of Interest: The authors declare no conflict of interest.

\section{References}

1. Usmani, Z.; Sharma, M.; Karpichev, Y.; Pandey, A.; Kuhad, R.C.; Bhat, R.; Punia, R.; Aghbashlo, M.; Tabatabaei, M.; Gupta, V.K. Advancement in valorization technologies to improve utilization of bio-based waste in bioeconomy context. Renew. Sustain. Energy Rev. 2020, 131, 109965. [CrossRef]

2. Estadística IN de E. Cuenta de los residuos/estadísticas sobre la producción de residuos. Año. 2017. Available online: https://www.ategrus.org/docuteca/informe/ine-cuentas-medioambientales-cuenta-de-los-residuosano-2017/ (accessed on 22 November 2020).

3. Consejeria de Agricultura P y DR. Cartografía de Invernaderos En Almería, Granada y Málaga. Sevilla. 2017. Available online: https://www.juntadeandalucia.es/export/drupaljda/Cartografia\%20_inv_AL_GR_MA_SEE. pdf (accessed on 22 November 2020).

4. Fundación Cajamar. Residuos Vegetales Procedentes de Los Invernaderos de Almería; Fundación Cajamar: Almería, Spain, 2016.

5. Reinoso Moreno, J.V.; Pinna-Hernández, G.; Fernández, M.F.; Sánchez-Molina, J.A.; Díaz, F.R.; Hernández, J.L.; Fernández, F.A. Optimal processing of greenhouse crop residues to use as energy and $\mathrm{CO}_{2}$ sources. Ind. Crop. Prod. 2019, 137, 662-671. [CrossRef]

6. Nagle, M.; Habasimbi, K.; Mahayothee, B.; Haewsungcharern, M.; Janjai, S.; Müller, J. Fruit processing residues as an alternative fuel for drying in Northern Thailand. Fuel 2011, 90, 818-823. [CrossRef]

7. Zinla, D.; Gbaha, P.; Koffi, P.M.E.; Koua, B.K. Characterization of rice, coffee and cocoa crops residues as fuel of thermal power plant in Côte d'Ivoire. Fuel 2021. [CrossRef]

8. Fernandez, A.; Ortiz, L.R.; Asensio, D.; Rodriguez, R.; Mazza, G. Kinetic analysis and thermodynamics properties of air/steam gasification of agricultural waste. J. Environ. Chem. Eng. 2020, 8, 103829. [CrossRef]

9. Pinna-Hernández, M.G. Solar-biomass hybridization in thermoelectric plant. Unpublished work. 2017.

10. Fudholi, A.; Sopian, K.; Ruslan, M.H.; Alghoul, M.A.; Sulaiman, M.Y. Review of solar dryers for agricultural and marine products. Renew. Sustain. Energy Rev. 2010, 14, 1-30. [CrossRef]

11. El-Sebaii, A.A.; Shalaby, S.M. Solar drying of agricultural products: A review. Renew. Sustain. Energy Rev. 2012, 16, 37-43. [CrossRef]

12. Perea-Moreno, A.J.; Juaidi, A.; Manzano-Agugliaro, F. Solar greenhouse dryer system for wood chips improvement as biofuel. J. Clean. Prod. 2016, 135, 1233-1241. [CrossRef]

13. Consejería de Agricultura P y DR. Líneas de Actuación de Las Consejerías de Agrícultura, Pesca y Desarrollo Rural y de Medio Ambiente y Ordenación Del Territorio En Materia de Gestión de Restos Vegetales En La Hortícultura de Andalucía. Sevilla. 2016. Available online: https://www.juntadeandalucia.es/export/ drupaljda/Lineas_actuacion_materia_gestion_restos_vegetales_horticultura_Andalucia.pdf (accessed on 22 November 2020).

14. Melero, J.A.; Iglesias, J.; Sánchez, A.G. Utilización de biomasa como materia prima de refinerías convencionales de petróleo: El caso de los bio-aceites. Ind. Química 2014, 12, 32-44. 
15. Pinna-Hernández, M.G.; Martínez-Soler, I.; Villanueva, M.J.D.; Fernández, F.G.A.; López, J.L.C. Selection of biomass supply for a gasification process in a solar thermal hybrid plant for the production of electricity. Ind. Crop. Prod. 2019, 137, 339-346. [CrossRef]

16. Asociación Española de la Normalización (AENOR). UNE-EN 14774-1; AENOR: Madrid, Spain, 2010.

17. Maroulis, Z.B.; Tsami, E.; Marinos-Kouris, D.; Saravacos, G.D. Application of the GAB model to the moisture sorption isotherms for dried fruits. J. Food Eng. 1988, 7, 63-78. [CrossRef]

18. Krokida, M.K.; Karathanos, V.T.; Maroulis, Z.B.; Marinos-Kouris, D. Drying kinetics of some vegetables. J. Food Eng. 2003, 59, 391-403. [CrossRef]

19. Agencia Estatal de Meteorología. Base de Datos Climatológicos. Available online: http://www.aemet.es/es/ (accessed on 22 November 2020).

Publisher's Note: MDPI stays neutral with regard to jurisdictional claims in published maps and institutional affiliations.

(C) 2020 by the authors. Licensee MDPI, Basel, Switzerland. This article is an open access article distributed under the terms and conditions of the Creative Commons Attribution (CC BY) license (http://creativecommons.org/licenses/by/4.0/). 